\title{
Augmented facets: A semiotics analysis of augmented reality facial effects
}

\author{
Federico Biggio ${ }^{1}$
}

\begin{abstract}
Augmented reality facial effects represent a new trend in social media communication based on 'short forms'. The article proposes a tripartite analysis: a semiotic analysis of digital facial effects used to empower the natural users' faces; a deconstructionist analysis of Spark by Meta, one of the major software applications to create such effects and, finally, a critical reflection on the practices prescribed by Spark and the stereotypical aesthetics of augmented selfies. The conclusion states that such forms of augmented reality effects must be conceived not as oriented to the cognitive improvement of users' performance but rather as forms of users' empowerment and self-awareness.
\end{abstract}

Keywords: face filters; facial effects; Instagram; Spark; augmented reality

\section{Introduction. A new trend in social media communication}

The article aims to account for an emerging form of digital creativity detectable in social media contexts and especially on Instagram. The article's specific object of inquiry is the digital facial effect (also called 'filter') used by social media users to enhance in different ways their natural faces' images in selfie production and sharing.

The semiotic analysis will focus on a specific typology of textual forms, which can be classified in the category of 'short forms' (Pezzini 2002; Montani 2020). Brevity should not be understood only as a material requirement (for example, the 13 seconds of Instagram Stories), but as a predominant textual form in social media contexts that testifies to a "compositional mode that loads of meaning in the first place the structuring of the text" (Montani 2020: 8).

1 Department of Excellence of Philosophy and Educational Sciences, University of Turin, Italy; Department of Hypermedia, University of Paris VIII Vincennes-Saint Denis; France; e-mail address: federico.biggio@unito.it. 
Among these 'short forms' we can insert licitly the so-called "selfie", which Del Marco (2017: 21) defines as a "reflexive shot, a photograph that a person makes to himself/herselves - in some cases with others and among others", by emphasizing both the object-reference of the visual representation and the social practice connected to its production: "[the selfie is] realized with a mobile device like a smartphone or a tablet or through a webcam, sometimes through the use of mirrors, object of sharing on social networks".

Short forms addressed in this article are selfies and Instagram Stories made with AR facial effects. There are digital facial effects of all kinds, ranging from beautification (effects that usually soften the skin, enlarge the eyes and make the face look thinner), to animal-like masks (effects that include, for example, animal ears and snouts), face swaps (an effect that swaps the faces of the people portrayed) and disfiguration of the face (similar to distorting mirrors). This is a global trend in selfie production that calls out for the visual semiotic analysis to understand the meanings of such "augmented images" as well as, from another perspective, the meaning-making performative practices of production and usage of such effects.

Mainly, AR facial effects work by adding partially transparent virtual layers to augment aesthetically the physical user's face displayed as a digital image within the device's screen. Undoubtedly, they constitute a form of entertainment and engagement for social media users. Nonetheless, they prompt the artists' creativity as several of these have begun to create facial effects by rediscovering surrealistic aesthetics ${ }^{2}$ that, in turn, have also enticed common users to engage with the creation of digital facial effects. This has become possible since the release of a series of software development kits, like Spark, which provide users with tools to detect, elaborate, manipulate and augment their selfies by creating their own personalized effects.

The analysis attempts to understand what may be considered as the "cause", or the "intentional reason" driving the users' agency to the production/adoption of facial effects for social media communication, in order to be used to overlap with the floating signifier of the selfie-image and, in turn, to achieve effects on the audience, in a regime of communication capitalism (Salisbury et al. 2017; Fuchs 2020).

At the same time, by simultaneously looking to the visual level of the augmented image and to the meaning-making performative practices of production and usage, facial effects production points to an "overlapping mechanism" carried out by the cooperation between the creative user and the computational entity, which encompasses the operation of computer vision and facial tracker engines. In particular, we focus on a specific software, Spark by Facebook (other popular apps like Facetune, Meitu and SwapCam, mainly focus on beautification).

2 See https://www.vogue.it/fotografia/article/the-art-of-filters; accessed on 22 February 2021. 
The production and usage of such facial effects relies on augmented reality, that is, the technology providing tools such as face models and trackers. Once launched, Instagram Stories' software detects, thanks to specific algorithmic functions, the user's face within the field of reality framed through the camera of the device (which previously has been instructed to recognize and understand through machine learning tecniques). In visual applications, for example, the computational instance makes an ecphrastic description of the surfaces (twodimensional or three-dimensional) that are present in the real environment. Simultaneous Localization and Mapping technologies, specifically, are the most important ones for augmented reality. They work by obtaining visual data from the physical environment in the form of points to feed the data into the machines. Instagram Stories' software, for example, detects input from predefined vector forms (for example, an oval to detect the face).

However, augmented reality, as it was conceived in its early days and as many commercial applications interpret its communicative potentialities, is by no means a medium for mere entertainment. Or rather, it was initially conceived as a worker-oriented technology related to the "personal empowerment" (Azuma 1997; Mann 1998) of the operational/cognitive performance of the worker ${ }^{3}$; around 2016, augmented reality by marketing strategies found its own medium specificity in popular applications able to increase users' knowledge of the surrounding environment by offering them, at the same time, an attractive, engaging, pervasive and emotional experience. Today, however, as our daily experience testifies, it is hard to conceive selfie effects in terms of forms of personal empowerment, intended as such. Augmented reality effects are daily used to make the shared images more attractive and appealing: for this reason, the so-called "Instagrammers", and more specifically the "influencers" and the "digital artists", are those who, in principle, make the most use of these compositional modes for the production and sharing of their own content.

We have to understand, therefore, to what extent augmented reality facial effects for selfies are conceivable as forms of augmentation, that is, of personal empowerment. We will try to answer this question, firstly by asserting that the augmentation does not refer only to the rational and logical empowerment of the user.

In fact, it is not the knowledge about one's face to be increased through the use of a selfie effect: these effects, rather, by virtue of their ability to increase the

3 The first augmented reality device prototypes were designed to increase the performance of workers and military personnel. The development of augmented reality has not, on the other hand, lost this identity: even after the failure of Google Glass for the public market, these devices have continued to be adopted in specialized fields, such as that of the manufacturing industry. 
degree of communicative effectiveness of the most important communication device in social media (i.e. the face), determine (or at least are potentially able to determine) a techno-aesthetic experience from which the user emerges continuously transformed.

\section{Empowering the face}

First of all, effects in augmented reality that are taken into account here concern only the augmentation of the face; but Spark (as well as Snap Kit by Snapchat) allows to create virtual overlaps in augmented reality of all kinds, which pose a difficult challenge to the categorizing instinct of semiotics. The question arises what criteria to use to bring together facial effects to add virtual make-up effects, psychedelic light in the selfie background and somatic traits of the opposite sex to user's face?

At the formal level, we might distinguish between aware and un-aware effects, figurative and non-figurative ones, in-real-time and in-hindsight-applied ones (Schipper 2018). Nonetheless, it is not possible to detect any kind of plastic continuity at the visual level of the augmented image, although it is possible to read these phenomena as expressions of a dominant communication logic in the production and sharing of selfies in social media: a "cumulative logic" (Rettberg 2014) that satisfies the needs of a culture of the spectacularizing of individualism (the cumulative process refers precisely to the constant production of visual texts which, once stored into one's page, let detect a digital identity of an individual user).

Moreover, a specific theme has been also that of the users' empowerment in relation to the possibility of manipulating their own project-oriented digital identity. Rettberg (2014: 12; my emphasis, F. B.) explained that "the ease and inexpensiveness of deleting digital images and taking new ones allows us to control the way we are represented to a far greater degree than in a photobooth or holding an analogue camera up to a mirror".

However, beyond the values of optimization and simplification that these tools bring to the praxeology of the user, the concept of 'empowerment' must be specified.

Rettberg also proposed the idea that the transformation of users' faces occurs mainly along with a certain degree of "strangeness": this is due to the fact that facial effects serve to gain one's digital image on social media, through a process of distinction from conventional selfies. For instance, when a face effect allows to augment selfies with rainbows coming out of the mouth, it gives the image a strangeness which makes subjecting oneself to other conventions of self- 
presentation seem pointless. The peculiar aspect of this practice is that it creates room for self-expression and experimentation beyond the norms. This is probably the reason for which facial effects fascinate us: according to Rettberg (2014: 26), they give the image a strangeness that defamiliarizes our lives and hence enables a critical and self-aware look at them.

The strangeness of facial effects, in this context, can be conceived as a vehicle of sense of "estrangement". For Shklovskij, estrangement is the process by which the poetic image "makes strange" the usual, the everyday, by operating a shift from the usual semantic series in which it is placed and presenting it in a new light, therefore transforming it into a poetic object: it has the function of "disautomatizing" the perception of reality by presenting new sides at different levels and according to different techniques (Šklovskij 1968[1917]).

The concept, then taken up by Brecht (1975), denotes also a "distancing" effect from the object of vision that arouses in the observer, an effect which no longer identifies realistically with the character, but captures its representativeness, its being the object of an aesthetic construction. In this last sense, the term 'estrangement' has to be conceived as a process by which users become able to "distance" themselves from the potential operation that AR facial effects provide for, to observe themselves critically from the outside, to develop a strategic competence to employ such effects for a project-oriented objective.

Our aim here is not to understand the augmented image produced by the selfie created as an artistic or poetic text; this would require an aesthetics that is not pertinent here. Instead, we want to underline the meta-operative component of linguistic production (Garroni 1977, 2005; Montani 2015) that in the specific practice of selfie production is expressed in the evaluation of a series of expressive choices (digital effects), provided by a wide repertoire of linguistic tools, to be used in selfie production practice. At this stage, the user "distances" him/herself from his/her image reflected on the screen of the device, imagines its aesthetic manipulation and, through the use of virtual facial effects, realizes it according to pre-constituted paths.

So, from a practical point of view, the act of sharing "augmented selfies" can be understood as a way to control the visual discourses of one's own, and hence, the gaze of the audience, as today digital self-representation can be intended as "conversational" (Rettberg 2014: 1). In fact, it cannot be denied that the digital availability of any content to improve the face visually is an aspect that, if correctly interpreted and adopted, may be decisive in empowering the communicative performance of a user on the network.

From a semantic point of view, the collaborative operation of a user and a computational instance determines an empowerment of the user's experience as 
the immense availability of expressive material in the Web (and, at the same time, the ease of use of linguistic tools) can be seen as an enhancement of the metaoperational possibilities of the user who, using effected selfies, simultaneously enables a critical and self-aware gaze on himself/herself ${ }^{4}$.

For instance, the effects (then banned) that allow users to visualize the appearance of their faces in case of a hypothetical facial surgery or as a forecast to sex change can represent an example of this tendency. In these cases, the augmented reality effects allow prediction, realize pre-visions, by visually realizing subjective or inter-subjective planning, but they also allow us to evaluate this prediction critically by deciding whether to realize it in the "real world". This mode of effects' design is even more evident in sponsored filters and lenses to augment users' face and surroundings with brand logos and paraphernalia.

In this regard, the interpretation given to these phenomena by Barnard (2016) proves to be of interest. Barnard focused on the practice of the selfie in the light of ideological and social meanings of a certain culture of individualism, and he exposes a material and affective conception of empowerment, particularly a postfeminist one. The selfie, according to him, functions as "an expressive celebration of the self by seeking to capture embodied experience" (Barnard 2016: 66) and as "a techno-cultural form" (Barnard 2016: 82): in the case of post-feminism, individuals who seek beauty alterations are necessarily empowered with more agency than previous generations, just because one can deduce, from the practice of their self-presentation, a prior understanding and problematization of the dominant aesthetic canons.

Other interpretations of effected selfies have been advanced, for, instance by Chae (2017), postulating that human beings have a basic instinct to compare themselves with others and to evaluate their own abilities and opinions and by proving that the selfie-augmenting phenomenon might negatively influence both presenters and audiences in online self-presentation, as "for presenters (individuals who frequently edit their own selfies) the discrepancy between reality and ideal might be problematic [...]. Individuals who often take selfies are likely to have an idealized virtual self-image, which might create discrepancy between reality and ideal" (Chae 2017: 375).

Thus, although by using face effects users might subject themselves to the gaze of the technology of augmentation and the stereotypical norms of selfpresentation (so, face filters would not empower the user); on the other hand,

4 However, Rettberg (2014: 26) stated later: "Instagram-style filters may make our selfies and photos of our everyday life seem unfamiliar, but the filter itself is repeated so often that the defamiliarisation effect wears off and becomes a cliché". 
though, augmented reality effects also instigate new ways of selfie creation that may be experienced as liberating one's digital image.

\section{Instagrammers and Spark users}

Before proceeding, we must define the specific properties of the user who uses virtual facial effects to empower his/her own selfie image. These users may be seen as a type of the 'prosumer'. Jenkins coined this concept in 2013, by retrieving from Toffler, denoting specific creative practices which concerned the public not as simply a consumer of pre-packaged messages, but as a subject who simultaneously consumes and produces contents circulating in media scenario. Mainly, prosumers' prototypical textual production practice involves the appropriation of multimedia contents on the Web and their remix through different types of software that lead to the creation of syncretic text forms, such as fandom movies, memes or digital effected selfies. Instagram users are prosumers as they use pre-packaged effects to augment their own selfies. According to Lev Manovich (2017: 117)5, Instagrammers can be said to own "the means of cultural production": this means, however, not only simply owing mobile phones and apps but, more importantly, "having skills in using these apps, understanding Instagram's rules and strategies for creating popular feeds, and being able to apply well these strategies in practice".

However, users augment their own selfies with digital effects which have in turn been produced by others. Prosumers are both Instagram users who adopt facial effects and Spark users who create such effects using a platform for content creation. Spark users can be equally conceived as the receivers of a commercial product, which allows them to create an augmented selfie and share it with the digital users' audience. They are equally spectators of a marketing strategy (and this is evident by looking at claims such as "Augment your space. Augment your style. Augment your sound. Augment your world", where 'your' explicitly refers to the subjective dimension of the experience in augmented reality $\left.{ }^{6}\right)$. Instagram users, on the other hand, are two-fold spectators, as they receive two products: the one produced by the company and the one produced by Spark users.

\footnotetext{
5 Manovich, Lev 2017. Instagram and Contemporary Image. Available at: http://manovich. net/index.php/projects/instagram-and-contemporary-image.

6 See https://sparkar.facebook.com/ar-studio/; accessed on 22 February 2021.
} 


\section{The face-software communication}

However, by looking strictly at the effects' production, the prosumer is not the only condition for facial effects use. We have to consider two further aspects of the phenomenon: on the one hand, the augmented reality software activity; on the other hand, the aesthetic canons imposed by a certain socio-cultural community.

As regards the former aspect, Spark represents both the software environment where effects are being created as well as the set of technical features (as face models and trackers) by means of which Instagram users augment their own selfies.

The Spark ${ }^{7}$ interface (Fig. 1) features an intuitive programming environment and a set of tools that allows prosumers to use a set of computational tools to create digital effects. It is characterized by a central section (called 'viewport') where "Euclidean" space is represented and a vectoral representation of the device camera and of the effect take place, with a window (called 'simulator') showing how the effect would look on a mobile device. Here, a plane is visualized in a 3D space, located in front of the device's camera, as well as a directional ambient light and a microphone: it is exactly in this interstitial space, organized in hierarchical and overlapped layers, that the "spectacle of augmentation" can take place.

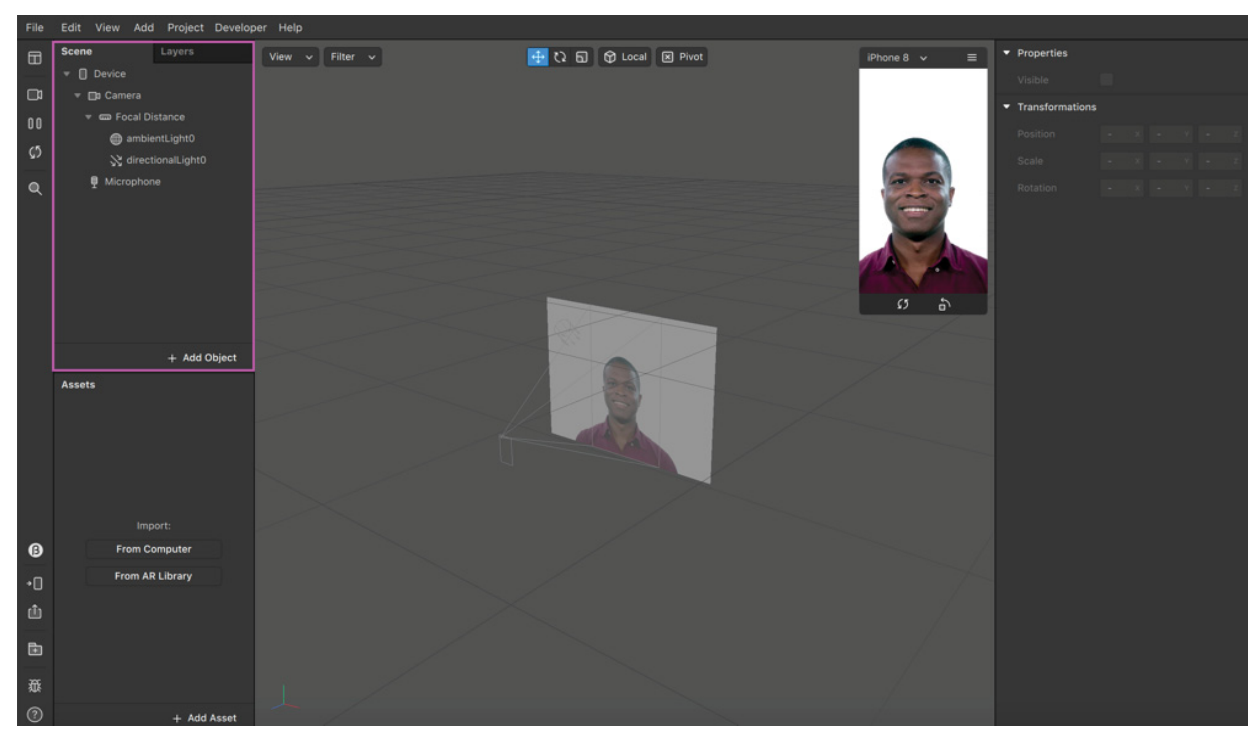

Figure 1. The interface of Spark AR Studio (https://sparkar.facebook.com/ar-studio/ learn/tutorials/introduction-to-spark-ar-studio; accessed on 22 February 2021).

7 By replying the success of Lens Studio by Snapchat, Zuckerberg's company released the Camera Effect Platform for AR Studio in 2017. The article focuses on the analysis of Spark AR Studio, the software developed by Instagram and then acquired by Facebook. 
Then, on the left, a double menu serves to store the objects, the trackers and the lights (the scene panel), and, finally, the materials, such as the textures and the scripts (the assets panel) imported by the prosumer. On the right-hand side, a multi-function panel displays functionalities according to the object selected in the right-hand panels. Finally, on the lower level, there is the patch editor, the section that serves to add interactivity and animation to effects by means of a system of boxes and links.

The main operation scheme to create a facial effect in Spark is to combine an 'object' - a face tracker - with a 'material' - an asset - by means of a face mesh. Once it has been uploaded, the face tracker becomes able to detect users' facial movements framed by the device's camera and then associated to the face gestures recognition engine. It responds to users' interactivity by displaying the digital effect. In this sense, we can state that Spark is featured by (and imposes on the productive process) a linguistic paradigm whose syntagmatic elements correspond to each body movement and gesture that users must actualize by interacting with the machine in a meaningful way.

Finally, a face mesh - that is a $3 \mathrm{D}$ model of a face - reconstructs users' expressions according to the detections made by the face tracker. In the assets panel, an image, an object or a texture, must already be associated to a material, in order to be later assigned to the face mesh and displayed in the viewport. Also in this case, the creative process has to be conducted toward a precise and standard format. For instance, when a texture has been uploaded, the user has to choose the material and the shader type by selecting among different grades of transparence: if the retouching mode has been chosen, the texture assumes the form of a patina, similar to the beautification filters to cover the imperfections of the skin. Gradually, from face paint mode to the blended one, the visibility of the effect becomes more pronounced. Although it is possible to regulate the grade of opacity of the layer for each type, the command name is still indicative of the previewed use.

The first pivotal point here is the detection of an actual linguistic code detectable through software analysis. The admitted facial gestures shape a sort of "syntax of interactivity" of the face-software communication.

For instance, it is possible to set an object appearing at the tapping of the screen or when the user face assumes a specific expression: facial movements such as eyes blinking, eyebrows raising or lowering, head rotation and shaking, or facial expressions such as a kissing or a smiling face, but also voice for audio inputs, are becoming ever more standardized gestures that spread in digital culture by stereotyping facial communication in social media contexts. An example is the so-called "side profile check", that is, the rotation of the head in front of the camera to show clearly the two profiles of the face. 
In semiotic theory, communication between two instances occurs only when both instances own knowledge (an "encyclopedic" one) that allows them to (1) formulate linguistic occurrences and (2) understand those formulated by the interlocutor.

Beyond the automatized-like effect of the users' natural communication with artificial-intelligence engines, adhering to certain interactivity schemes prescribed by the software (or by the effect), result, as a consequence, in the increase of the awareness of mediation, as well as the development of a critical self-judgment of one's appearance that is certainly more pertinent in the field of social and psychological sciences. This self-awareness plays a central role in the competitiveness between users of social networks (Chae 2017).

Although the repetition of a movement in front of a camera may recall the modus operandi of the so-called "challenge", the performance of these gestures does not aim to take an active part in a process of collective support of ideologically featured causes, but aims to express the users' unique and unrepeatable aesthetic appearance through more or less objective evidence, in the production of visual texts (e.g. selfies) that can be sanctioned by the community of users both positively and negatively. In fact, the creation/adoption of specific facial effects can also be sanctioned by the social community as well as by the owners of the platform (i.e. Facebook). For example, it is a fact attested in psychological studies (Ramphul, Mejias 2018) that the spread of facial effects has led more and more users, especially the youngest, to evaluate the possibility of plastic surgery that allows them to touch up the shape of the eyes (that is, to have "cat eyes"), to enlarge the volume of the lips or to shrink the nose. To denote this type of "disorder" the expression 'Snapchat dysmorphia' has been coined. These considerations have led to several negative sanctions of facial augmentation practices with virtual effects, such as banning of cosmetic surgery effects as created by Daniel Mooney, prohibited since these promoted plastic surgery and harmed people's mental health (Fig. 2). 


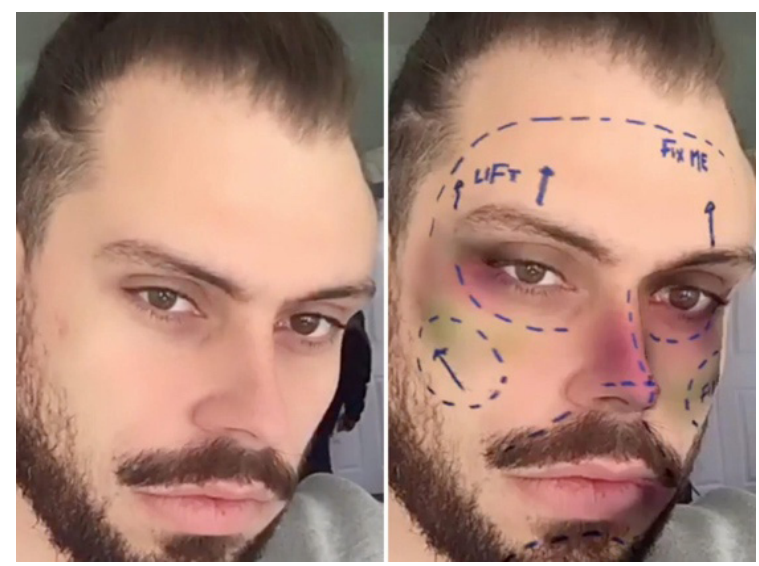

Figure 2. Daniel Mooney's plastic surgery effects, retrieved from https://www.insider.com/ instagram-cosmetic-surgery-filters-removed-2019-10; accessed on 22 February 2021.

\section{The awareness of the empowerment and the un-awareness of the mediation}

We might distinguish between the awareness of the empowerment and the awareness of the mediation. The former refers to the recognizing of the effect within a selfie-image: it occurs always, as the effect is created/adopted by users themselves. The latter, however, refers to the recognizing of the presence of an effect within another user's photo (moreover, to the "presence" of the computational activity which may be attested just from the weirdness of certain effects): the awareness of the mediation is an unnecessary condition since many effects, e.g. make-up or beauty ones, try to achieve maximum possible truthfulness: "Digital images start to look "natural" to us; moreover, even technologically embedded visual effects, including those that heavily modify facial reproductions, start to acquire an aura of ineluctability" (Leone 2020: 6). FaceTune and Meitu represent the apex of this trend.

Hence, the negative sanction of the community, similarly to the psychological one, does not move from the assumption that the user is unaware of the empowerment. Digital users live as "immersed" within a software culture, they know how programs work, how to manipulate computational elements and how to act synergically with algorithmic entities in order to express themselves in social media contexts (Manovich 2017). Rather, the users are aware of the empowerment, but they are un-aware of the mediation. The negative sanction moves from the assumption that the user is un-aware of the mediation, that is, the presence of a 
database which has been created by Facebook, the in-between actor which provides the tools for the empowerment.

By searching for an ever-better effects and by confronting those employed by themselves with those used by others, users would risk to lose the grasp of the all-encompassing totality of the whole mediation, from which emerges a clear formal homogeneity that translates the whole database into an aesthetic canon to be respected. According to Manovich (2019: 6), "while the gradual AI integration into phone cameras and sharing sites may contribute to a decrease in aesthetic diversity, the simultaneous addition of more and more controls to cameras and photo apps may have the opposite effect".

On the other hand, the platform that fosters users toward such experiences persuades them with seemingly endless collections of effects. It embodies a textual organization that has established "inter-objectual user positions" which convince them that they can manipulate the face in any way, without limits to the imagination. However, "disintermediation through technology inevitably leads to standardization, which is completely at odds with the promise of autonomy that the technological market sells" (Leone 2020: 6).

Hence, by adopting a critical media standpoint "artistic" practices of creation on Spark, as well as the usages of digital effects by Instagrammers cannot be conceived in the same way of free expression articulating computational matter, in the same terms of an artistic gesture. Although some kind of constrictions can always be traced in artistic traditions, the AR facial effects' creation can be read as more constrictive of the former, at least because of their ownership.

Rather, they must be conceived as user-friendly applications which transform computationalism and creation in entertainment processes, whose applications' user engagement is a fundamental component of the provided programs of actions.

\section{The paradox of user-friendly computational creativity}

Spark's interface is a high-level one and the software itself should be conceived as a "company product" (which owns a certain aesthetic coherence or, at least, requires it) rather than a software development kit. Spark is not properly a Software Development Kit (SDK) but rather a media platform. A Software Development Kit is a collection of tools provided by a graphical interface, which can vary in its complexity and allows its users to create homogeneous applications which interact with the hardware of the computational instance without them having to program the deepest interfaces. The variety of application complexities that different SDKs allow to create is at the same time an index of the SDK's accessibility. A SDK that in 
large part provides the writing of computer code can be considered less accessible than one like Wordpress in which you get standard results, but these are always finished, even from a simple manipulation and assembly of "textual blocks".

Spark similarly features a very intuitive and accessible interface (if we take into account the basic skills that Instagrammers possess, the reason is understandable). For example, since the launch of the program, Spark features a template window (Fig. 3) that proposes different effects templates for a quick start of the creation, e.g., the make-up, the face decoration, the face mask or the $3 \mathrm{D}$ animated poster (but also a blank project): these are conceivable as a standardized action program.

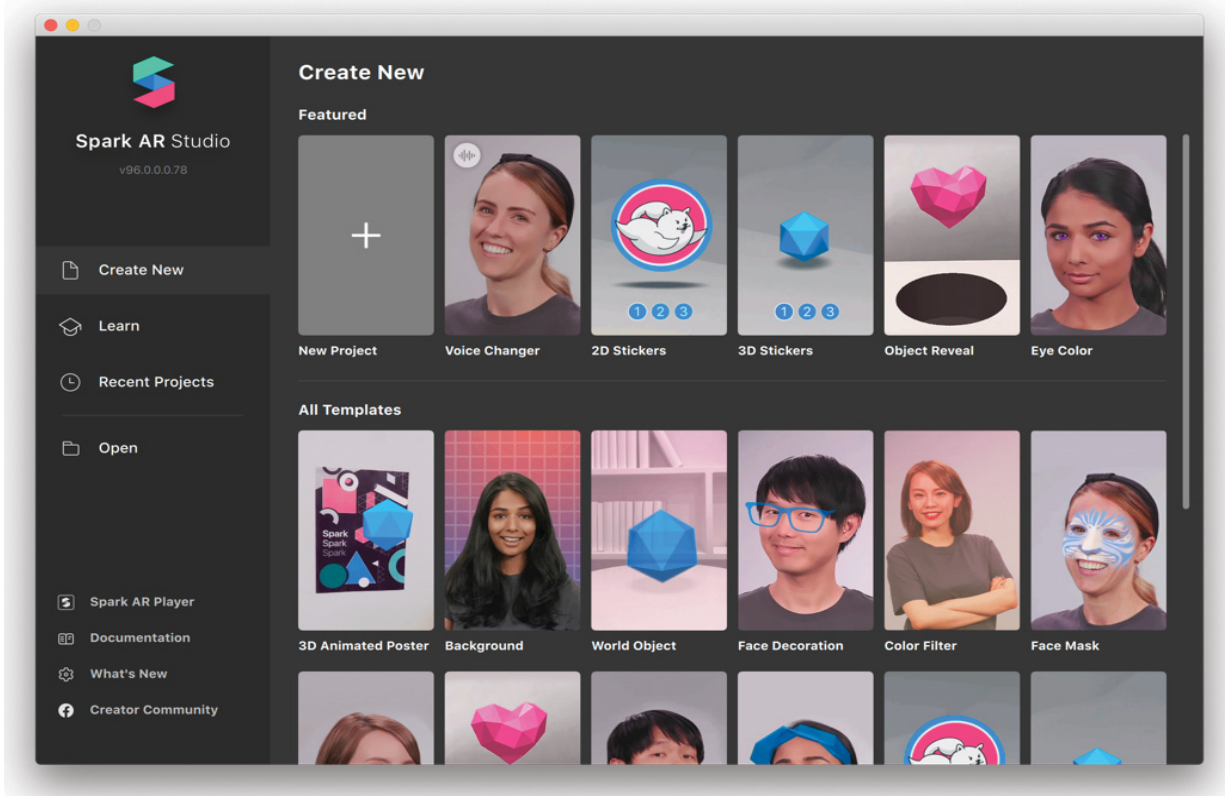

Figure 3. The template window of Spark, retrieved from https://sparkar.facebook.com/ ar-studio/learn/articles/fundamentals/templates\#opening-a-template; accessed on 22 February 2021.

In this sense, on the one hand, Spark is a media platform, a public database that users can access in order to retrieve elements and techno-linguistic tools to create their own original content; on the other hand, the linguistic identity of this media platform, that is, the aesthetic and ethical codes that digital effects' seriality constitutes, can at the same time be traced back to a sort of "standardization" of textual production practice. However the easiness and immediacy of the interface does not necessarily correspond to a limitation of the expression potentiality of 
the user. Spark has been designed mainly for users with poor programming skills who need to create amazing content as quickly as possible. Users learn to explore Spark interface step by step thanks to a huge quantity of online tutorials provided by Facebook. These texts constitute a second (elementary) form of "prescription" of the creation process, which leads unavoidably to a homologation of the aesthetics of digital effects: the tutorials concern, for instance, the creation of stereotypical face effects and have been configured precisely as a sort of "coaching services", useful to become artists and to achieve the success within the social media community.

Moreover, it is meaningful that nowadays Spark is not just featured within the platform Facebook Developers, but it has become an application for common users' entertainment. Its Facebook Community, the "Spark AR Community" group, nowadays counts over fifty thousand members and the Facebook Page "Spark AR Creators" has over eighty thousand likes. Here, Spark creators daily share facial effects created and discuss these issues with one another. The definition of the platform's standards can thus be related to the establishment of a community, both a social, a cultural and an economic one. This happened at the birth of the World Wide Web, where the "http" protocol allowed different servers to communicate with one another; this is happening today in cases like Spark in which the supply of face assets by companies allows users to create their content with their preferred software, but having just the provided ones as a base standard and sharable models.

Finally, the capitalization of creativity led by Facebook, capable of enforcing adherence to certain aesthetic and moral canons, concludes with the approval process of the effect by the owners of the platform. Here, it is not the community but the Hub of the application (in this case Meta) where the users upload their creation to operate as a "sanctioning instance" whose role is to approve the wellbeingness of the digital effects, according to a strict set of policies. Once the effects' production process is concluded, the user must submit the effect to the platform, by means of the Hub, in order to make the effect in the platform accessible and usable. Although it could not be defined as an actual censorship process, there is no doubt that a certain further filtering operation has occurred.

In this regard, Rettberg (2014: 20) proposed also a broader definition of the term 'filter': in today's algorithmic culture, the filter is not simply the kind that removes skin impurities, but it is instead a pervasive metaphor for the ways in which technology can remove certain content and it can alter or distort the users' natural faces.

The paradox of user-friendly computational creativity lies precisely here. These forms of digital creativity clearly express a will of liberation from aesthetic stereotyping, as well as a free expression of one's own creativity, but this ideal 
is pursued through the use of creative tools that are "constrictive". Barnard (2016: 82) points at this tension and proposes the notion of '(dis)empowerment paradox': in this context "I have identified a (dis)empowerment paradox where such expression may feel empowering to the individual(s) controlling the camera while concurrently conforming to and reifying oppressive, hegemonic norms".

\section{Conclusion: Aesthetic empowerment and interactive imagination}

Spark effects are not similar to aesthetic filters for digital cosmetics: whereas the latter are useful to improve a photograph in as realistic and transparent a way as possible, the former feature a higher artificiality. If in the 19th century the photographic technique established the absolute transparency of the technology (and thus the un-awareness of the mediation), as well as the suppression of the traces of reproduction of the medium, in the case of computer graphics creativity through augmented reality we witness a predominant return to the awareness of the medium, of its virtual aesthetics as well as of its creative potentialities - both in the production process and in the use in social media contexts - which in no case can be considered to be oriented just to the improvement of an image, but rather to an original reinterpretation of its potential uses. Already Photoshop retouching, for instance, was not just a way of improving photographs, but a means for individuals' artistic expression, useful to enhance the creative gesture. The same goes for augmented reality effects.

At this point we might recover the original idea attributed to augmented reality, but we should admit that the "personal empowerment" of the operational/cognitive performance of the user is not at stake here. Instead, the empowerment relies on the platform's ability to provide users with an attractive, engaging, pervasive and emotional archive of virtual facial effects to create an enhancing visual experience.

Although in some make-up effects the objective of the empowerment is truthfulness, the main feature of Spark's face effects is evidently the ability to create explanations of the increased reality's creative potentialities through the genius of the creator. For this reason, the use of emerging digital media like augmented reality for artistic purposes is very meaningful. This trend represents a form of "technological enchantment" which aims to foster human-made technical creativity, a childish and irrational sensibility that leads users to recover a primordial dimension of existence where techniques are at the service of humanity, and serves to discover and to interpret the strangeness in the world. In an article about endosemiotic features of augmented reality, Wamberg (2012: 471) stated 
that "this reawakened and even empowered indexicality of augmented reality has certain similarities with natural habitats and can indeed be understood, I would claim, as a relinking to natural layers of experience". For Wamberg, by reactivating as the main sign of indexicality, augmented reality emphasizes the "proactivity" of interaction and rehabilitates forms of performance related to the magical feats.

So, this analysis intended to affirm positively the communicative effectiveness of facial filters in augmented reality that, unlike the (much more widespread) beautification effects, have the possibility to be strategically employed by users to emphasize and empower their communication practices in social media contexts. However, this can only happen as long as the digital effect was considered as a strategic technology, and not as a technological product capable of compromising the users' natural understanding of the real world. In the context of Instagram, this poses a risk of standardization and aesthetic repetitiveness.

The justification for the hypothesis of an anthropological gain comes from the aesthetic theory of Pietro Montani, modelled on Garroni's and Malafouris' thesis on material engagement with the tools of languages. Thinking of augmented reality, Montani pointed to the activation of an interactive imagination, by describing it as a fundamental competence in the evolution of the human being, essentially rooted in sensoriality. In this regard, Augmented Reality can be conceived as a creative operation able to rethink and re-imagine the natural world in which the user is the protagonist, to act on and through "forms of technical life capable of transforming into a non-programmable world, albeit in accordance with rules" (Montani 2014: 77). Over thirty years of computational culture have taught users that everything that is digital has been programmed, and, at the same time, this has been fuelling the idea that everything, including reality itself, is a priori programmed. It is from this consideration that computational creativity can be understood as an individualistic, yet still positive counter-programming strategy of expression. By putting proactively a filter on our selfies, or framing them by placing them in a blog or an Instagram feed, users see themselves and their surroundings as if they were outside of ourselves, by re-inventing the real world, by imagining it in an interactive way, by re-projecting it in an un-restricted way.

I would like to conclude this reflection with an open question which concerns a final aspect that is not addressed here for it is not directly relevant. To what extent would the aesthetic empowerment of the user be conceivable or comparable to the personal empowerment of augmented reality traditionally intended, if seen as related to the gnoseological increase, a quantitative and qualitative one, of user performance in the flesh? Answering this question would require further investigation of the concept of empowerment, by focusing on the dis-empowering aspects, which Wamberg (2012: 474), for example, defined as "frustration with 
nature and its artificial protheses in technology", in order to understand how the subject of empowerment, previously anesthetized by dis-empowerment, may again be empowered through facial augmentation performances.

\section{References}

Azuma, Ronald 1997. A survey of augmented reality. Presence: Teleoperators and Virtual Environments 6(4): 355-385. https://doi.org/10.1162/pres.1997.6.4.355

Barnard, Stephen 2016. Spectacles of self(ie) empowerment? Networked individualism and the logic of the (post)feminist selfie. Communication and Information Technologies Annual 11: 63-88. https://doi.org/10.1108/S2050-206020160000011014

Brecht, Bertolt 1975. Scritti teatrali I. Torino: Einaudi.

Chae, Jiyoung 2017. Virtual makeover: Selfie-taking and social media use increase selfieediting frequency through social comparison. Computers in Human Behavior 66: 370376. https://doi.org/10.1016/j.chb.2016.10.007

Del Marco, Vincenza 2017. L'immagine in rete. Selfie, social network e motori di ricerca. Roma: Edizioni Nuova Cultura.

Fuchs, Christian 2020. Communication and Capitalism: A Critical Theory. London: University of Westminster Press. https://doi.org/10.16997/book45

Garroni, Emilio 1977. Ricognizione della semiotica. Roma: Officina Edizioni.

Garroni, Emilio 2005. Immagine, linguaggio, figura. Roma: Laterza.

Jenkins, Henry; Ford, Sam; Green, Joshua 2013. Spreadable Media: Creating Value and Meaning in a Networked Culture. New York: NYU Press.

Leone, Massimo 2020. Digital cosmetics. Chinese Semiotic Studies 16(4): 551-580. https:// doi.org/10.1515/css-2020-0030

Mann, Steve 1998. Humanistic computing: "WearComp" as a new framework and application for intelligent signal processing. Proceedings of the IEEE 86(11): 2123-2151. https:// doi.org/10.1109/5.726784

Manovich, Lev 2019. AI Aesthetics. Moscow: Strelka Press.

Montani, Pietro 2014. Tecnologie della sensibilità. Estetica e immaginazione interattiva. Milano: Raffaello Cortina.

Montani, Pietro 2015. Prolegomeni a una "educazione tecno-estetica". Mediascapes Journal 5: 71-82.

Montani, Pietro 2020. Emozioni dell'intelligenza: Un percorso nel sensorio digitale. Milano: Meltemi.

Pezzini, Isabella 2002 (ed.). Trailer, spot, clip, siti, banner: Le forme brevi della comunicazione audiovisiva. Milano: Meltemi.

Ramphul, Kamleshun; Mejias, Stephanie 2018. Is "Snapchat dysmorphia" a real issue? Cureus, 10(3). https://doi.org/10.7759/cureus.2263

Rettberg, Jill Walker 2014. Seeing Ourselves through Technology: How We Use Selfies, Blogs and Wearable Devices to See and Shape Ourselves. London: Palgrave MacMillan. https:// doi.org/10.1057/9781137476661

Salisbury, Meredith; Pooley, Jefferson 2017. The \#nofilter self: The contest for authenticity among social networking sites. Social Sciences 6(10): 2002-2016. https://doi.org/ $10.3390 /$ socsci6010010 
Schipper, Meike 2018 “A Whole New Way to See Yourself(ie)": Exploring How Face Filters Transform the Practices of Selfie Creation. [Unpublished PhD Dissertation.] Utrecht: Utrecht University.

Šklovskij, Victor 1968[1917]. Larte come procedimento [Iskusstvo kak priëm]. In: Todorov, Tzvetan (ed.), I formalisti russi. Torino: Einaudi, 73-94.

Wamberg, Jacob 2012. Toward a (re)onstructed endosemiotics? Art, magic and augmented reality. In: Ekman, Ulrick (ed.), Throughout: Art and Culture Emerging with Ubiquitous Computing. Cambridge: The MIT Press, 465-478.

\section{Семиотический анализ цифровых масок дополненной реальности}

Цифровые маски, использующие технологию дополненной реальности - новый тренд общения в социальных сетях, предпочитающего «краткие формы». В статье предлагается трехсторонний анализ: семиотический анализ цифровых масок, используемых для усиления естественных возможностей лиц пользователей; деконструкция Spark, одного из основных приложений для создания подобных эффектов; наконец, критическое рассуждение о предписанных Spark практиках и стереотипной эстетике дополненных селфи. В заключении утверждается, что такие формы эффектов дополненной реальности должны быть задуманы не как ориентированные на когнитивное улучшение работы пользователей, а скорее как формы расширения возможностей и самосознания пользователей.

\section{Augmenteeritud tahud: augmenteeritud reaalsuses ette tulevate näoefektide semiootiline analüüs}

Augmenteeritud reaalsuses esinevad näoefektid esindavad uut suunda "lühivormidel" põhinevas ühismeediasuhtluses. Artiklis esitatakse kolmeosaline analüüs: loomulike kasutajate nägude võimestamiseks kasutatatavate digitaalsete näoefektide semiootiline analüüs; Facebooki pakutava Sparki, ühe olulisema sellisete efektide loomiseks kasutatava tarkvararakenduse, dekonstruktivistlik analüüs, ning viimaks kriitiline mõtisklus Sparki pool ette kirjutatud praktikate ja augmenteeritud selfide stereotüüpse esteetika üle. Kokkuvõttes leitakse, et seesuguseid augmenteeritud reaalsuse efektide vorme ei tule pidada kasutajate soorituse kogntiivsele parendamisele orienteerituks, vaid pigem kasutajate võimestamise ja eneseteadvustamise vormideks. 